\title{
Improving Freshman Retention in an Engineering Technology Program
}

Dr. Ralph Sprang, Pennsylvania State University, Erie

Dr. Ralph Sprang teaches Electrical and Computer Engineering Technology at Penn State Erie, the Behrend College. He earned the PhD in Electrical Engineering from the University of Pittsburgh, the MSEE from the Johns Hopkins University, and the BSEE from the Ohio State University.

\section{Mr. Stephen A. Strom, Pennsylvania State University, Erie}

Stephen Strom is a lecturer in the Electrical and Computer Engineering Technology department of Penn State Behrend, and holds a B.S. in electrical engineering from Carnegie Mellon University. His career includes over thirty years experience in designing and programming embedded systems and has multiple patents for both hardware designs and software algorithms 


\section{Improving Freshman Retention in an Engineering Technology Program}

Abstract - High freshman attrition in engineering programs is a significant and growing concern. In 2010 and 2011, less than $41 \%$ of first year freshmen received a grade of $C$ or better in first semester technical major courses at Penn State Erie, the Behrend College. Retention rates increased by $15 \%$ to $25 \%$ for the first semester of implementation for the programs described in this paper, fall 2012.

Existing events and programs that are targeted at freshman did not significantly improve retention. The two existing programs are the Freshman Interest Group (FIG) and FastStart. The FIG program houses students in dormitories by major and provides a peer mentor but does not engage students living off-campus. The FastStart program holds a few social events per year to bring students and mentors together, but requires the freshman student to take the initiative to join the program and maintain contact with his or her mentors.

Programs that support development of community and increase student engagement can improve freshmen retention. These programs build community among students, peers, and faculty by "forcing" students to participate. The students are required to learn each classmate's name and to complete group work with every other student during the course of the semester. A student-led club provides social, academic, and technical events led by upper class mentors.

\section{Introduction}

First semester freshman attrition in engineering technology programs at Penn State Erie, The Behrend College (PSU-Erie), is a significant and growing concern. Between 2010 and 2011, less than $41 \%$ of engineering students achieved a grade of $C$ or higher in their first semester technical courses in the major. Freshman enrollment in this program ranges from 25 to 30 students, and this retention rate therefore reduces class size to 10 to 12 students. Our threshold for canceling classes is 10 students, and this retention rate endangers the success of this program at this campus.

Existing events and programs that are targeted at freshmen have not significantly increased retention. Two programs offered to incoming freshman are the Freshman Interest Group (FIG) and FastStart. The FIG program houses students in dormitories with other freshmen and assigns roommates and location by major. In addition, an upperclassman peer mentor lives in the dormitories with the freshman and participates in the freshman seminar class. Prior research cites benefits of a FIG program such as improved class attendance and improved retention, but the increase is limited [1]. Tibbetts notes that FIG programs engage resident students who register for the program and live in the dormitories, but do not engage students living outside of the dorms [1]. Carrell cites the exclusion of non-resident students as a downfall of residence-based programs and suggests that significant retention improvement requires the formation of a cohort inclusive of all students [2]. The PSU-Erie FIG consists of dormitory residents who select the program, and therefore does not engage the significant number of students who live with their parents or in other off-campus housing.

The second program, FastStart, focuses on cultural and social events. FastStart is a campus-wide program that groups a freshman student with a faculty mentor and an upper class student mentor. To participate in FastStart, the freshman student must first learn about the program and then take the initiative to join the program and attend introductory events. As a result, this program generally draws students willing to make the effort but does not engage more passive students who don't take the initiative to get involved. In addition, if the freshman student does not quickly form a strong relationship with the mentors, the freshman student tends to stop participating in the program.

For the fall 2012 semester we set out to develop more effective programs to improve freshman retention. Prior work at other universities shows that First Year Engineering Experience (FYEE) programs can significantly improve retention. Bullen evaluated a project-based FYEE program that reported a 33\% increase in retention as late as the seventh semester [3]. Baillie researched peer tutoring as a means of improving retention [4], and Daempfle noted that peer tutoring had the added benefit of overcoming student's negative perceptions of faculty [5].

A common theme in these and other prior retention improvement efforts is the formation of community. In this context, we use the word community to express the forming of a friendly cohort of students in the same major. This cohort includes the freshmen students in the major as well as peer mentors. Astin finds that the students' peer group is the most influential source in improving student retention [6] and Budny notes the importance of a friendly group that is at least partially peer-led 
[7]. Building this sense of community provides a group where students can feel comfortable and are able to express their views outside the classroom, providing an environment that addresses multiple student issues and therefore improves retention [7].

The programs described in this paper were first implemented in Fall semester 2012. After this one semester, freshman retention increased to $55 \%$, an increase of $15 \%$ to $24 \%$ relative to the two previous fall semesters. This paper explains the programs developed, discusses results, and explores how to further improve retention.

Method

Peer mentors were recruited to assist in development of the programs as well as to lead some activities. Peer mentors were initially recruited from the sophomore class, since they completed the freshmen courses in the prior year and thus had recent experience similar to that of the incoming freshmen, enabling them to relate better to the freshmen. Selection criteria included extracurricular activities, hobbies, and participation in other programs. Students selected had broad interests and were already enthusiastic about the program. Although academic performance was considered, the other criteria were considered more significant and were weighted more heavily in the evaluation process.

Students were invited to serve as peer mentors, and two students were selected. One of the selected students is a consistent top performer academically, while the other student is a C level student with extensive hobby background and interests in computers and electronics. In addition, one senior level mentor was selected on the basis of academic performance, to ensure adequate knowledge for exam reviews.

Faculty teaching loads were assigned to ensure freshman students had a different instructor in each course the first semester. Feedback from the 2011-2012 freshman class expressed concern about having classes with different instructors in the spring 2012 semester. Students felt it was important to build relationships with the spring semester faculty prior to that semester so they could focus on the coursework. Assigning different faculty to teach lecture and lab allowed students to work with most of the faculty members during the fall semester.

In labs, students were encouraged to help build community by working with different partners and learning each other's names. The lab instructors assigned different lab partners each week to ensure each student worked with all of the other students during the course of the semester. In addition, one of the lab instructors played "the name game" with the students. In this game, the class sits in a circle, the first person says their name, and then the second person repeats the first person's name and appends their own name to the list. Each person in turn repeats the prior names and appends their own name until the list of all names is formed. As originally conceived, the circle would be travelled a second time, so that every student has to repeat every other student's name from memory, with prompting as needed. In practice, it proved impractical for most students to learn 20 to 25 names during the first lab class, so we started lab with the name game for just the first two labs. By the third lab, most students knew the names of more than half the other students and the students were becoming frustrated, so the game was discontinued at that point. Playful threats in later classes to resume playing of the name game elicited smiles and chuckles from the students while reminding them they needed to learn the names of their classmates.

A student-led club was formed to further build community. The student club was formed as a means to include nontraditional students and others who live off-campus and create engagement opportunities with the campus-resident students. This club was formed and run by the peer mentors with faculty acting in a primarily advisory role. This club provided educational opportunities such as exam reviews, homework assistance, and study skill training sessions, fun activities such as game nights, and introductory technical projects and activities targeted at energizing student interest in the major as well as demonstrating applications of the course material.

One example club activity was a "brown bag competition" that was conducted early in the semester. Students were given a brown bag containing an assortment of parts. Students were informed that there were "extra" resistors in the bag and advised to select the extra resistors, determine their values, and then return those parts to the correct stock drawers. This part of the activity reinforced learning the resistor color code in an informal and fun setting.

Next the rudimentary wiring of an LED was explained, and the students were invited to wire a simple circuit to light the LED. When the students succeeded in illuminating their LED, one of the mentors approved their project and then encouraged the students to build a different second circuit that could illuminate at least two LEDs.

\section{Discussion}

Faculty observation of the freshman students as well as both solicited and unsolicited student comments suggest that the goal of building community was achieved. Faculty observed that students were more engaged and willing to ask questions in 
class, spent more time talking and working with other students outside of class, and generally seemed to have formed a cohort that included all of their classmates. Students demonstrated a higher level of interest in the program, with more than half the students asking faculty for help with outside projects.

Students expressed enthusiasm for the student club and asked the student mentors to include more advanced projects. As originally planned, projects were based on simple discrete components, such as the brown bag example explained previously. In response to student requests, more advanced projects were added, including simple Arduino-based microcontroller projects. The freshman students successfully completed these projects, suggesting they will be better equipped for the sophomore introductory microcontroller class in the Fall semester.

Sophomore student mentors initially led exam review sessions in conjunction with a graduating senior mentor. The graduating senior was able to handle student questions during the review more effectively than the sophomore students, but by the end of the semester, faculty members were leading the exam review sessions. One of the learning outcomes from this experience is to inform the students leading the review sessions well in advance about the topics to be covered, to give these students time to refresh their knowledge of the material and effectively handle freshman student questions.

The freshman students requested that all faculty attend the club meetings. When some faculty did not attend a club meeting, students complained about their absence. As a result, contrary to the conclusions drawn from prior research [Budny, Astin], students in this program preferred that faculty attend the club meetings and participate as part of the community. Strangely, the opportunity to repeatedly beat one of the faculty members in games such as Halo on game nights seemed to build community as much as some of the other activities. Apparently the ability to best a weak player in a computer game builds confidence among freshmen.

Freshman retention increased to 55\% for the Fall 2012 semester, 15\% to 24\% greater than prior years. One significant factor in this increase is the implementation of these programs. However, other factors may have affected retention as well, though the impact is believed to be minor. Two known factors include transposition of the order of teaching for two chapters in the circuits book and the normal year to year variation between groups of students. The chapter transposition is believed to have had minimal impact, though we lack definitive data to confirm that conclusion. The year to year variation in retention rates for prior fall semesters was in the range of $10 \%$ for years when we made no specific effort to improve retention, suggesting that the retention effort alone resulted in at least a $5 \%$ to $14 \%$ improvement in retention.

Student leadership for the student club dissipated in the following year. At the time the student club was started, four strong and enthusiastic students led the club and were highly motivated to keep it active. As these students became more involved in other activities, they attempted to pass leadership of the club to students in the sophomore class. Although some students agreed to participate, they did not have the same enthusiasm and the club held few events. Academic performance for the freshmen was is the same range as the freshmen in 2011, before implementation of the improvement effort. This result seems to confirm that the community aspect and specifically the club played the greatest role in improving retention and academic success.

Conclusion

Programs to build community among students can significantly improve freshman retention. Implementing programs that build community by "forcing" students to meet, socialize, and work with their classmates and most of the faculty in conjunction with peer-led fun, technical, and social events caused student engagement and retention to increase. A student-led club greatly improves academic success and retention, and performance suffers if the club becomes inactive.

Faculty involvement in these programs seems to be critically important. Students are more comfortable and confident when faculty lead exam reviews and students want to engage with faculty outside of class. Building community among the students must include the involvement of all faculty members to be successful.

This initial effort did not achieve the goal of $80 \%$ retention of first semester freshmen, so there is more work to do. Students admitted to the program have previously demonstrated strong academic success and should be capable of succeeding in the program. Our goal is to increase the retention rate to at least $80 \%$ in the first semester while maintaining academic rigor. While a few students may not be well-prepared for college or are not sufficiently motivated to successfully engage technical material in their first semester, these students are the exception rather than the norm. For those students who do show an interest and aptitude in the material, effort must be put forth to give these students a reasonable and improved chance to succeed. 
The programs listed in this paper represent a first step in improving retention within the program and future effort should build on this success. Future efforts to improve community may include a student-organized trip, enhanced student fundraising, and additional student projects involving both freshmen and upper class undergraduate students to help relate real-world applications to the theory taught in the classroom.

\section{References}

[1] Tibbetts, S. G., “Freshman Interest Groups In Criminal Justice Education,” Journal of Criminal Justice Education, vol. 14, no. 2, pp. 213-228, 2003.

[2] Carrell, S. E., Fullerton, R. L., and West, J. E., "Does Your Cohort Matter? Measuring Peer Effects in College Achievement,” Journal of Labor Economics, vol. 27, no. 3, pp. 439-464, 2009.

[3] Bullen, F. and Knight, D., “The role of the first year engineering experience (FYEE) course,” World Transactions on Engineering and Technology Education, vol. 4, no. 2, pp. 219-223, 2005.

[4] Baillie, C., “Addressing first-year issues in engineering education,” European journal of engineering education, vol. 23, no. 4, pp. 453, 1998.

[5] Daempfle, P.A., “AN ANALYSIS OF THE HIGH ATTRITION RATES AMONG FIRST YEAR COLLEGE SCIENCE, MATH, AND ENGINEERING MAJORS,” Journal of College Student Retention, vol. 5, no. 1, pp. 37-52, 2003.

[6] Astin, A. W., and Astin, H. S., Undergraduate science education: The impact of different college environments and the educational pipeline in the colleges, Higher Educational Research Institute, U.C.L.A., Los Angeles, CA,, 1993.

[7] Budny, D., Paul, C. A., and Bon, L., "The Impact Peer Mentoring Can have on Freshman Students." pp. 1-6. 